\title{
The Diversity of Models as a Means to Better Explanations in Economics
}

\author{
N. Emrah AYDINONAT \\ TINT, Centre for the Philosophy of the Social Sciences \\ Department of Political and Economic Studies \\ University of Helsinki, Finland \\ aydinonat@gmail.com
}

Draft | 21.02.2018

\begin{abstract}
In Economics Rules, Dani Rodrik (2015) argues that what makes economics powerful despite the limitations of each and every model is its diversity of models. Rodrik suggests that the diversity of models in economics improves its explanatory capacities, but he does not fully explain how. I offer a clearer picture of how models relate to explanations of particular economic facts or events, and suggest that the diversity of models is a means to better economic explanations.
\end{abstract}

Keywords: theoretical models, explanation, diversity of models, howpossibly reasoning, functions of models

JEL Codes: B40, B41

\section{Introduction}

Although it is no secret that economists work with a diverse set of models, this has rarely been brought up in methodological debates concerning the explanatory import of theoretical models in economics. Recently, however, Harvard economist Dani Rodrik (2015) emphasized the importance of having a diversity of models. In Economics Rules, Rodrik argues that what makes economics powerful despite the limitations of each and every model is its diversity of models. 'It is a model, not the model!' is the motto of the book. This motto suggests that no model can explain everything. Rather, each model is contingent- that is, it depends "on the specific postulated conditions" (2015, p. 25) —and has limited explanatory power. Rodrik suggests that the diversity of models improves the explanatory capacities of economics, but he does not fully explain how. The purpose of the present paper is to offer a clearer picture of how models relate to explanations in economics, and to suggest that the diversity of models is a means to better explanations. In this paper, I am mainly interested in how a diversity of models contributes to explanations of particular economic facts or events.

How do models relate to explanations, and how does diversity contribute to an explanation? There are two possible ways to interpret Rodrik's account. The first interpretation is that diversity implies that economists have a rich set of models that could apply to different contexts. Explanation requires finding the right model for the particular explanatory task, hence the particular context. Thus, explanation starts from a set of diverse models, proceeds with a model selection process, and ends with the "right" selected model providing an 
explanation. In this reading, diversity of models is valuable mainly because it increases economists' chances of finding the right explanatory model.

The second reading of Rodrik is that explanation requires finding and utilizing the right set of models for the explanatory task at hand. The resources of multiple models are utilized in an explanation. Models help economists in assembling and developing possible answers for a given explanation-seeking question, and also in checking the validity of these explanations. This reading suggests that the relation between models and explanations is much more complicated than the first reading suggests. Moreover, if multiple models enter into an explanation, this means that the explanatory task is much more complex than the first interpretation suggests. If the phenomenon is the result of multiple causal factors and if there is no single model that can capture all these factors, then progress might be slow and a conclusive explanation may not emerge in the end. In sum, this interpretation implies that the contribution of the diversity of models to the explanatory capacities of economics goes beyond increasing the probability of finding the right model.

In the present paper, I am primarily interested in providing a descriptive account of how models are utilized in explanations in economics in practice. I argue that the second interpretation of Rodrik's account is more in line with the practice, and amend his account to explicate the link between models and explanation. I also highlight the different ways in which having a diversity of models could contribute to explanations. For example, many economic explanations utilize a diverse set of models that helps in specifying and measuring the explanandum (the thing to be explained), identifying possible explanatory factors that may account for the explanandum, and assessing the plausibility of possible explanations. My portrayal of the practice relies on an account of models that considers models as tools for how-possibly reasoning. Models help us ask and answer a series of what-if questions about the phenomena in question. This helps in determining the possible explanatory factors that could enter into an explanation and, for a given explanatory task, in populating a range of possible causal scenarios, or possible explanations. Providing a correct explanation requires determining the actual causes of the fact to be explained, and uncovering the actual causal story or structural dependencies based on the available menu of possible explanations (Ylikoski and Aydinonat, 2014). Portraying models as tools for how-possibly reasoning helps us see how having a diversity of models could improve the explanatory capacities of economics and increase the ability of economists to provide better explanations. This is why I suggest that diversity is a means to better explanations. Nevertheless, relying on a large set of unrealistic models also poses a number of interesting challenges. Obviously, one cannot discuss these challenges unless one acknowledges that economists work with a diverse set of models and that economic explanations often utilize multiple models. The present paper, then, should be considered as taking this first step. For this reason-and also because of space constraints-I do not discuss these challenges except briefly in the conclusion.

The plan of the paper is as follows: The second section surveys Rodrik's account of models and explanation in economics. In the third section, I argue that Rodrik's account implies that economists utilize multiple models in their explanations. The fourth section maps Rodrik's terminology onto my own terminology and suggests that models should be considered as tools for how-possibly reasoning. In the fifth section, I explain the different roles that models play in the process of explaining particular facts or events (i.e., in providing singular explanations). In the sixth section, I discuss how a diverse set of models could help in developing better explanations in economics. The seventh section concludes the paper. 


\section{Rodrik on models and explanation}

Rodrik (2015) thinks that much of the criticism of economics is based on misunderstandings of economic models and how economists use them in their explanations or in policy-making. Before Rodrik, a number of economists attempted to provide us with accounts of economic models that were supposed to obviate the misunderstandings concerning what economists actually do (e.g., see Gibbard and Varian, 1978; Sugden, 2000, 2009, 2011, 2013; Gilboa et al., 2014). What makes Rodrik's contribution different is his double emphasis on the diversity and limitations of theoretical models in economics. He accepts that each model has limited explanatory power, but he also argues that the explanatory capacity of economics as a whole is not limited by the limitations of individual models, because the diversity of models increases its explanatory power. But how does a diverse set of models - each of which has limited explanatory ability — enhance the explanatory capacities of economics? Let us have a closer look at Rodrik's account of economic models.

First, contrary to the instrumentalist accounts that were inspired by Friedman (1953), Rodrik argues that the realisticness of some assumptions matters: "Unrealistic assumptions are OK; unrealistic critical assumptions are not $\mathrm{OK}^{\prime}$ " (2015, p. 213). Rodrik emphasizes the importance of critical assumptions throughout the book (2015, pp. 18, 27, 29, 94), arguing that "what matters to the empirical relevance of a model is the realism of its critical assumptions" (2015, p. 94). But what is a critical assumption? Here is Rodrik's definition:

$[\ldots]$ an assumption is critical if its modification in an arguably more realistic direction would produce a substantive difference in the conclusion produced by the model. (2015, p. 27)

Many assumptions may be harmless in this sense. Others can be critical for some types of questions the model answers but not for others. (2015, p. 94)

Rodrik's definition is not self-explanatory. Let us temporarily define a critical assumption as an assumption concerning an important property of the phenomenon at stake given the explanatory or policy task. For example, whether firms are assumed to have market power or not may be a critical assumption given a policy task intended to advise a government on the effects of a price cap. It is difficult to predetermine all critical assumptions of a model (because they are relative to the task at hand), but the important point here is that Rodrik suggests that the applicability of a model depends on its ability to capture an important property of the phenomenon, given the task. With this preliminary definition, we can move on, but note that how critical assumptions are conceived is relevant to how we understand the contribution of diversity to the explanatory capacities of economics. I discuss this point in Section 3.

Second, the function of the assumptions of a model is to isolate causal mechanisms and relevant dependencies (Mäki, 1992, 2011; Rodrik, 2015, pp. 25, 43, 86, 114, 213); or put differently, models allow economists to study the effect of certain factors in isolation from the influence of others. Rodrik argues that models function like experiments in this sense. They are like thought experiments (Mäki, 1992, 2005; Morgan, 2002; Rodrik, 2015, pp. 24, 114). However, models do not aim to account for all potential causal mechanisms at the same time. Rather, models "isolate and identify causal mechanisms, one at a time" (Rodrik, 2015, p. 25).

Third, for this reason, each model can only provide a partial account of the phenomenon concerned (on this, also see Aydinonat, 2008). "Each economic model is like a partial map 
that illuminates a fragment of the terrain" (2015, p. 8). Especially, "they leave us short of a full explanation of real-world phenomena when many causes might be simultaneously operating" (Rodrik, 2015, p. 114). Every model focuses on different aspects of the real world, and highlights different dependencies and background conditions.

Fourth, Rodrik argues that "the diversity of models in economics is the necessary counterpart to the flexibility of the social world. Different social settings require different models" (2015, p. 5). It is because of the limitations of models and the complexity of the social world that we need multiple models to navigate our way into the real world.

Finally, as a consequence and as a matter of fact, economists develop and work with a diverse set of models (on this, also see Ylikoski and Aydinonat, 2014). There are models of the same type of phenomena that focus on different aspects, mechanisms, background conditions, etc., and models of different types of phenomena. In short, as Rodrik argues, "economics encompasses a large and evolving variety of frameworks, with different interpretations of how the world works and diverse implications for public policy" (2015, p. ix).

So how does diversity improve the explanatory capacities of economics? A preliminary answer emerges from this introduction to Rodrik's account: to navigate through the complex social world, one needs many models, each of which is applicable to different contexts. That is, explaining various aspects of the real world requires using various models. It is for this reason that diversity enhances the explanatory capacities of economics.

\section{Diversity and explanation}

Rodrik considers models as investigative tools that help us understand and explain the real world. He also sees models as policy-making tools. Throughout the book, Rodrik vacillates between these two perspectives, which give us slightly different views on how diversity contributes to economics. Consequently, there are two possible ways to interpret Rodrik on how models contribute to explanations.

The first interpretation is as follows: a diversity of models enriches the model pool and increases the probability of finding the right model for the explanatory task. That is, in the end, one "right" model will be selected for the explanatory task, and it will do the explanatory work. Rodrik's discussion of model selection in particular supports this reading.

The chapter on model selection starts with the example of a car engine failure (Rodrik, 2015, pp. 85-86). Rodrik asks the reader how she would go about locating the problem. He argues that although all parts of the engine are causally and structurally relevant to the correct operation of the car, starting with a study of a full-size replica model of the complete working engine and ripping the car apart are not good strategies. Rather, he suggests, one should start with a set of models of engine failure that highlight possible engine problems that one might encounter, and search for evidence suggesting which of these problems is more likely to be the actual problem. He argues that in this process "what helps is knowing what to focus on" and models guide us in choosing what might help. Because each model isolates a different mechanism, each will point to a different mechanism as a cause of the problem. But, Rodrik argues, "the dominant mechanism in explaining the failure is only one of these", and this leads us to the right or correct model (2015, pp. 17, 61, 85, 86). Accordingly, he argues, "selecting the right model to apply is key" (2015, p. 61).

From all this, it appears that the role of a diversity of models is to increase economists' chances of finding the right model for the task. Once the right model is found, it does the explanatory work. However, this conclusion cannot be right because Rodrik also argues that 
social reality is complex and multiple causal mechanisms are at work more often than not. Because each model is limited, a single model cannot always provide us with a satisfactory explanation that takes into account all the relevant factors that produce the phenomenon. This brings us to the second reading of Rodrik's account.

The fourth chapter of the book, where Rodrik discusses the types of explanation-seeking questions that economists try to answer, supports another reading. Rodrik suggests that when economists answer why-questions or big timeless questions, they utilize a set of models to provide an explanation; that is, an explanation does not always involve selecting the "right" model. Economists utilize a set of models in their explanations. Explanation, then, requires selecting the right set. That set might, of course, contain only one model for some explanatory tasks, but it does not have to.

As I have indicated above, the interpretation of what Rodrik means by critical assumptions is relevant to this second reading of how models relate to explanations. Recall that Rodrik's definition implied that an assumption is critical if changing it produces different results. This could be determined by altering the model's assumptions and checking whether the result holds. Philosophers call this derivational robustness analysis (Woodward, 2006; Kuorikoski, Lehtinen and Marchionni, 2010). ${ }^{1}$ For example, consider a textbook Hotelling location model (Varian, 2009). The model assumes that two profit-maximizing sellers are located in a bounded linear market where customers are evenly distributed, prices are given, and sellers compete in location. The result of the model is that sellers locate at the center of the market (which represents minimum product differentiation). If we change the assumption that prices are given and let the sellers compete both in price and location, the result of the original model will not obtain. Thus, following Rodrik we could argue that the assumptions concerning the non-existence of price competition are critical to the Hotelling model.

If we were to follow the first reading above, this would mean that the Hotelling model would only be applicable to situations in which this assumption holds. However, as Rodrik also argues, the real world is complex, and the contexts in which this assumption holds are rare. Rather, there is usually some degree of price competition together with competition in product characteristics, such as location. To explain the amount of product differentiation, economists commonly use multiple models. While the Hotelling model alerts us to a tendency of firms to produce similar products, other models tell us that there is another tendency that pulls firms away from each other. For this reason, to explain the degree of product differentiation in a particular market one may need to utilize multiple models and feed these models with relevant contextual details (e.g., see Borenstein and Netz, 1999; Netz and Taylor, 2002).

Moreover, robustness analysis cannot determine criticality of an assumption by itself, because Rodrik thinks criticality relates to applicability, being context dependent. Consider a case where a model's results are very sensitive to changes in its assumptions. For example, Hotelling's original model (1929) is very sensitive (not robust) to alterations in many of its assumptions. Changing the number of sellers from two to three, altering the shape of the market from a line to a circle, changing the functional form of the transportation costs, etc.

\footnotetext{
1 Note that what Rodrik means by diversity is not limited to the families of models produced by robustness analyses. A set of models implied by robustness analysis would contain models that share a common core mechanism and differ only slightly from the original model in other assumptions (e.g., tractability assumptions). However, Rodrik also talks about models that are fundamentally different from each other; including models that focus on different causal mechanisms.
} 
changes the results of the Hotelling model (e.g., see Eaton and Lipsey, 1989). If these assumptions were to determine the applicability of the model, the Hotelling model would not be very useful. This is not the case, however. The Hotelling model alerts us to a tendency and it is explanatorily relevant if this tendency is found in the real world. As I have tentatively suggested above, the criticality of an assumption can only be judged given the explanatory (or, policy-relevant) task at hand. Besides, as this discussion suggests, there might be many models that could be relevant to a given task.

In sum, the second reading seems to be more in line with Rodrik's discussion of explanation in economics. In fact, Rodrik provides us with an example of multiple models being utilized in explaining the rise of inequality in the United States, which I discuss in Section 5.

\section{Answering explanation-seeking questions}

An explanation has two main components; an explanans (set of propositions that do the explaining) and an explanandum (the thing that is explained). Ideally, factors cited in the explanans should make us understand why the explanandum phenomenon exists, happened, came about, etc. An explanation stating that $\mathrm{X}$ explains $\mathrm{Y}$ implies that $\mathrm{X}$ is causally responsible for $\mathrm{Y}$, and that if $\mathrm{X}$ did not happen, $\mathrm{Y}$ would not happen. ${ }^{2}$ Given this working definition, we can distinguish between two types of explanation in economics. Some explanations explain stylized facts, regularities or generalizations. Let us call these theoretical explanations. ${ }^{3}$ Economists also explain particular facts or events. Let us call these singular explanations.

Rodrik (2015, pp. 113-145) distinguishes between three different kinds of questions that economists answer: what questions, why questions and big questions. Unfortunately, this is neither a good classification nor an exhaustive one. Nevertheless, let us have a closer look at what Rodrik has in mind.

- What-questions. According to Rodrik, what questions are the proper domain of models (2015, p. 115). Economic models help us answer questions like the following: "What is the effect of A on X? For example: What is the effect of an increase in the level of the minimum wage on employment?" (2015, p. 114). How does a model answer a what question? Given the conditions specified by its assumptions, a model shows how the isolated causal mechanism produces the model's results (2015, pp. 114-115). Note however, there is no guarantee that what we observe in the model (the relation between A and X) is a good guide to what is happening in the real world. Thus, additional steps are required if we want to use a model's answer to a what-question in an explanation (of a real world phenomenon). As I argue shortly, a more appropriate characterization of the kinds of questions that models help us answer is that models help us with what-if questions. Moving from what-if questions (or Rodrik's what-questions) to why-questions is not a simple matter.

2 For reasons of brevity and clarity, I only discuss this causal account of explanation in this paper. Nevertheless, the general argument is applicable to non-causal explanations as well.

3 For the causal account of explanation I use here, see Woodward (2003). For the basics of explanation, see Ruben (2012). There is no general agreed-upon definition of theoretical explanations. The distinction I make here is based on the explanandum of singular and theoretical explanations. If the explanandum is a particular fact or event, I consider it as a singular explanation. If the explanandum is some sort of generalization or a regularity, I define it as a theoretical explanation. The reader could also use the term 'generic explanations' instead of 'theoretical explanations'. The naming is not important for the purposes of this paper, but the distinction is. 
- Why-questions. Rodrik considers the answers to why-questions as "explanations of an observed set of facts or developments". The aim of such explanations is "to shed light on particular historical episodes" (2015, p. 115). Thus, in our terminology answers to Rodrik's why-questions are singular explanations. However, note that one can also ask why-questions concerning regularities and general phenomenaanswers to which would be theoretical explanations. Rodrik classifies this latter type of why-questions as big questions.

- Big questions. Then there are big timeless questions, such as "what determines the distribution of income in a society?" and "what are the determinants of the wealth of nations?" In our terminology, answers to these question would be theoretical explanations. However, there are also big and hard to answer questions about particular facts. For example, consider a favorite question of economists: why did the West get rich, but not the rest? An answer to this question would constitute a singular explanation and it is different from questions like "what is value?", "what are the determinants of national wealth?", or "why do prices increase when there is an increase in demand?"

Economists provide us with singular explanations (small and big) and theoretical explanations. The focus of this paper is on how answers to Rodrik's 'what questions' relate to singular explanations in economics. How do we move from models to singular explanations?

An important step for seeing how models are used in explanations is to understand that economic models help us answer what-if-things-had-been-different questions (Woodward, 1984, 2003, Morgan, 1999, 2001, 2002; Ylikoski and Aydinonat, 2014). ${ }^{4}$ What if there is an increase in an individual's budget? What if the price of the substitute good changes? What if there is a supply shock? etc. That models help us answer what-if questions is well in line with Rodrik's account. In fact, Rodrik himself lists a set of what-if questions when he tries to show how models guide our intuition concerning the effects of immigration (2015, p. 57). The important thing to note here that "an economic model [...] is a thoroughly artificial construct that unfolds in our minds only" (2015, p. 23). That is, a model helps us ask and answer what-if questions, but these what-if questions still concern this construct, the modelworld. For this reason, models are tools for exploring possibilities; helping us see what might happen, what interactions are likely to be important, and so on. In Rodrik's words, "economic models alert us to a variety of scenarios" (2015, p. 209) and "open our eyes to counterintuitive possibilities and unexpected consequences" (2015, p. 46).

If models are tools for how-possibly reasoning, what models provide us with can be considered as a list of factors (mechanisms, conditions, exogenous factors, etc.) that might be explanatorily relevant. Each model alerts us to a set of explanatory factors and informs us about the settings under which they might be relevant. A diverse set of models, then, gives us a menu of explanatory factors together with guidelines concerning when we are likely to observe them in action. Another way to put this is as follows. Models provide us with causal mechanism schemes that we can use in constructing our explanations. In explaining particular

\footnotetext{
4 This depiction of models is obviously related to the theory of explanation that considers explanations as answers to what-if-things-had-been-different questions (Woodward, 1984, 2003). At first sight, the relation between models and explanation appears to be simple: models help us answer what-if questions, hence they help us explain. Nevertheless, as this paper illustrates, the relation between models and explanation is more complex than this first impression suggests.
} 
facts, causal mechanism schemes are used as building blocks for causal scenarios that might bring about the particular fact under investigation (Ylikoski and Aydinonat, 2014). Hence, models help us produce a menu of causal scenarios, or a menu of possible explanations (cf. Rodrik, 2015 , p. 21,74, where he talks about a menu of models). The task of providing a singular explanation requires determining the plausibility of these causal scenarios. To provide a correct explanation one needs to verify that the mechanisms and factors suggested by the set of relevant models are actually responsible for the phenomenon of interest. The diversity of models provides us with "a menu to choose from," but we also "need an empirical method for making that choice", argues Rodrik (2015, p. 74). Verification plays an important role in moving from models to explanations in economics.

To sum up, if we follow Rodrik's discussion of how models help us explain, it turns out that the added benefit of diversity of models concerns the ability to assemble possible explanations using multiple models. Rodrik provides a nice example: the case of rising inequality in the U.S. In discussing this example, Rodrik (2015, p. 117) assesses "the relative contributions of different models, and show[s] how such a process generates insight even when it does not produce a conclusive and widely agreed theory". In what follows, I use Rodrik's example to explicate the several ways in which models contribute to an explanation.

\section{How diversity contributes to explanations}

We are interested in how models are used in producing singular explanations in economics. Broadly, models contribute to explanations in economics in two ways. First, they provide us with the explanatory factors that go into the explanans. Second, they contribute to the final product, the explanation, by providing other services. For example, models can be used as benchmarks, as frameworks for thinking about possibilities, tools for measurement or prediction, and so on (Pielou, 1981; Wimsatt, 1987; Odenbaugh, 2005). In order to come up with an explanation, we often utilize some of these model services. The case of the explanation for rising inequality in the U.S. is a nice illustration of how models contribute to an explanation, and why having a diversity of models can be an asset for social scientists.

A review of the literature on rising inequality in U.S. suggests that models help us in (i) identifying and describing the explanandum, and making the explanandum more precise; (ii) identifying the set of possible explanatory factors and explanations; (iii) verifying the mechanisms and implications of possible explanations, (iv) stitching the available explanations together; and (v) assembling the final explanation. Let me explain.

First, models help in identifying and describing the explanandum. Often it turns out that the initial explanation-seeking question conceals many smaller questions. For example, increased inequality in the U.S. could mean many different things. We could ask a variety of questions: why did the incomes (or wealth) of the top $1 \%$ of the population increase relative to that of the $99 \%$ ? Why did the incomes of skilled workers increase relative to unskilled workers? Why did the wage gap between workers in manufacturing increase? and so on. ${ }^{5}$ Moreover, answering one of these more specific questions requires formulating the explanandum more precisely. For example, we might be interested in inequality in wage incomes rather than capital incomes; or we could investigate why the relative wages of educated workers are increasing as a proxy for the change in the relative wages of skilled workers. And so on. Economists tackle an explanation-seeking question like the one about inequality by addressing a "smaller", more precise and more manageable version of it. Hence answering

\footnotetext{
${ }^{5}$ For a review of different aspects and measures of inequality, see Levy and Murnane (1992).
} 
the original question (e.g., about inequality) often takes time and requires the input of many economists. Different economists focus on different but related questions and address different aspects of the problem. The role of the diversity of models at this stage of the process is helping each economist to specify their explanandum more precisely. For example, models in labor economics guide economists about different types of income and labor, determination of wages, and the supply of and demand for skilled and unskilled labor, etc. The literature on the U.S. income inequality shows that since 1990s economists have been busy identifying and describing their explanandum using multiple models (for a survey, see Gordon and Dew-Becker, 2008).

The task of identifying and describing the explanandum also requires figuring out ways to measure what we wish to explain. Measurements in economics are shaped by economic models as well as statistical models. For instance, a measure of inequality must be used in our example. Since there are several such measures, one needs to use one that is appropriate for this task. Inequality between the incomes of workers and those of owners of other production factors can be traced using the wage share (labor share) as a measure. Using this measure would presume a model of the economy and a set of complicated statistical methods to measure GDP_-which is itself a construct of economists (Coyle, 2014). Alternatively, one could use the Gini coefficient, a common and convenient measure for income (and wealth) inequality. The Gini coefficient is frequently defined using a model of the distribution of income or wealth; the Lorenz curve (Lorenz, 1905; Giorgi, 1990). In sum, models also enter this first stage of explanation as tools for measurement; they help us answer how-much questions (Boumans, 2006, 2009) and specify the explanandum in a measurable way. It is worth noting that difficulty of measurement and availability of data sometimes determine how the explanandum is formulated and what aspects of the phenomenon are considered.

Second, models help in identifying the set of possible explanatory factors and explanations. Let us assume that we have identified and described the explanandum as precisely as we can. Let our question be the following: why did the incomes of skilled workers increase relative to the incomes of unskilled workers in the 1980s in the U.S.? Also, assume that we have decided to use the level of education as a proxy for skill. The basic supply-demand model is central to thinking about the possible causes of an increasing wage gap between skilled (higheducation) and unskilled (low-education) workers, and to formulating possible causal scenarios that could explain it. By way of helping us ask and answer what-if questions such as what if the relative supply of unskilled workers rises, the basic supply-demand model helps in exploring possibilities and locating the channels through which relative wages might change. This helps us to list possible causes and formulate possible causal scenarios. See, for example, how a labor economics textbook lists these possibilities.

The major phenomenon we must explain is the widening gap between the wages of highly educated and less-educated workers, and our basic economic model suggests three possible causes. First, the supply of lesseducated workers might have risen faster than the supply of college graduates, driving down the relative wages of less-skilled workers. Second, the demand for more-educated workers might have increased relative to the demand for less-educated workers. Finally, changes in institutional forces, such as the minimum wage or the decline in unions, might have reduced the relative wages of less-educated workers. (Ehrenberg and Smith, 2012, pp. 542-543; emphasis added) 
This textbook example is in line with the practice of economists. For example, Bound and Johnson (1992) follows a similar strategy in listing alternative possible explanations in their article entitled "Changes in the structure of wages in the 1980's: an evaluation of alternative explanations."

Although the basic supply demand model is a good starting point, it is not enough. One also needs to think about why supply and demand might be changing. This requires looking at other models. Economics has a plethora of models that could help us. For example, a standard textbook in labor economics (e.g., Ehrenberg and Smith, 2012) provides us with a model of the firm and its demand for labor, diverse models of individuals and the supply of labor (e.g., the labor-leisure choice model, labor-household production model), job-matching models (e.g., models of compensating wage differentials), models of individual investment in skills (e.g., the human capital investment model), models of minimum wages and union wage effects, etc. Beyond labor economics, there might be other relevant models, such as the Heckscher-Ohlin (H-O) model, which show how other factors (such as international trade) might influence the relative wages of skilled workers. These models guide our thinking concerning factors that might explain rising inequality and help in formulating the following possible explanations, extensively discussed in the literature:

(i) Globalization: Globalization might have influenced the wage gap through openness to trade, international competition, offshoring, foreign direct investments (influencing relative demand for skill), and immigration (influencing the relative supply of unskilled workers).

(ii) Technological change: Skill-biased technological change, increasing skill requirements, and technologies that replace unskilled labor (influencing the relative demand for skilled workers) might have caused the wage gap.

(iii) Institutional factors: Institutional factors, such as policies concerning unionization, minimum wages, tax rates and education could potentially influence the relative wages of skilled workers and change the supply of skilled labor via their effect on college enrolments.

The important point here is that a single model cannot help us formulate these alternative causal scenarios. Knowledge of a wide variety of different but related models is needed. Two examples will suffice. For example, the $\mathrm{H}$-O model enters into the picture because it suggests a possible causal scenario by which the relative wages of skilled workers increase (Rodrik, 2015, pp. 139-140). According to the model, increasing openness to trade causes the U.S. to export skilled-labor intensive goods and import low-skilled-labor intensive goods. Accordingly, the demand for skilled labor increases, and demand for low-skilled labor decreases in the U.S. This explains the increasing relative wages of skilled workers. However, the $\mathrm{H}-\mathrm{O}$ model implies that in the U.S.'s trading partners, relative wages of skilled workers will not increase. An alternative to the $\mathrm{H}-\mathrm{O}$ model is the Feenstra-Hanson $(\mathrm{F}-\mathrm{H})$ model $(1995,1997)$. Contrary to the H-O model, the F-H model shows that rising wages of skilled labor in both developed and less-developed countries might be consistent with capital flows between these countries (Feenstra and Hanson, 1995, 1997). It alerts us to the importance of offshoring and FDI as possible causes of the wage gap.

Third, theoretical models help in verifying the mechanisms and implications of possible explanations. Note here that I am suggesting that models help in verifying possible explanations; it is not models that are verified, but possible explanations suggested by the set of available models. Rodrik talks about model selection as a process through which the assumptions and implications of a model are verified. Hence, it is possible to interpret him 
as saying that models are verified. This, however, is not always the case. Consider the basic supply-demand model we referred to earlier. Economists do not try to verify this model in trying to determine the most plausible explanation. On the contrary, they take the implications of this model as granted and use it to verify the plausibility of the available possible explanations. For example, Ehrenberg and Smith (2012, pp. 542-551) ask the reader what if the change in the relative supply of skilled labor was the source of the income inequality. They use the standard supply and demand model to answer this question, since if there were a reduction in the relative supply of skilled workers, the relative wages of skilled workers would increase. However, this change would also imply that the relative quantity of skilled (unskilled) workers in the labor market would decrease (increase). This implication is taken for granted and helps them verify the plausibility of alternative explanations. They conclude that because the employment of unskilled workers did not increase in the U.S., the change in supply cannot be the dominant explanatory factor. Similarly, Levy and Murnane (1992, p. 1342) talk about an "Economics 1 test" in order to "test explanations" or "explanatory theories" (1992, p. 1341).

A similar verification process helped economists dismiss the possible explanation suggested by the H-O model because its implications were not supported by data (Rodrik, 2015, p. 140). This however did not mean that the H-O model was rejected. On the contrary, because the implication of the model was taken for granted, it was concluded that international trade could not be solely responsible for the increasing relative wages of skilled workers. However, an alternative, the F-H model, suggested another possible explanation. Its implications were consistent with these findings and with other sources of data (Feenstra and Hanson, 1995, 1997). Thus, globalization and international trade remained relevant as possible explanations for income inequality in the U.S.

These examples explain why I suggest that theoretical models help us verify explanations, rather than talking about a model verification process. However, it is important to note that the verification process often involves specifying an empirical model that could help identify the plausibility of alternative explanations. As such, it could depart from a basic model, such as the supply-demand model, and include additional variables in order to test for other alternative explanations. For example, because the standard model assumes that wages reflect the productivities of different groups of workers, it cannot account for divergences from this competitive norm due to institutional factors. To test for institutional factors, an additional variable also needs to be introduced into the empirical model (e.g., see Bound and Johnson, 1992). Here we need not go into the details of the methodology of this verification process. Highlighting the fact that theoretical models play an important role in helping economists specify empirical models and test for alternative explanations is enough for our purposes.

Verification of the existence of explanatory factors cited in possible causal scenarios could be quite straightforward for some cases. For example, a possible causal scenario that includes the immigration of low-skilled workers would be rejected if there were no immigration. The process of verification will be more complex for others because of the lack of data, difficulty in identification, etc. However, even if the factors cited are in existence, and hence verified, this does not imply that a possible causal scenario is the actual one. This is why additional verification of causal scenarios using the implications of relevant models is needed, as we have seen above.

Verifying a possible causal scenario might also involve questioning its applicability to other related explananda. For example, for a while the explanation for the rising wage gap between skilled and unskilled labor favored by most economists appeared to be skill-based 
technological change (SBTC). The SBCT scenario seemed to explain developments in the 1980s well. However, it turned out that SBTC was not consistent with later trends, such as the stabilization of wage inequality between skilled and unskilled workers despite continued technological change, and its implications were not fully consistent with other aspects of wage inequality (i.e., other explananda, such as gender and race wage gaps) (for an extensive review, see Card and DiNardo, 2002). This cast doubt on its explanatory power. Hence, economists concluded that it could not be the only explanation of the increasing inequality between skilled and unskilled workers in the 1980s. For this reason, they pursued an alternative to the SBCT model which assumed that technology influences wages through demand for skilled workers. It is possible that technological change influences wages through more complex channels (Ehrenberg and Smith, 2012, p. 547). In fact, recent work suggests that technological progress might have had a polarizing effect in that the employment of skilled and unskilled workers increases at the expense of middle-skill workers (Autor, 2010).

Evidence also suggested that institutional factors, such as policies concerning minimum wages (a decreasing real minimum wage) and unionism (declining union membership) might have also contributed to the wage gap (Card and DiNardo, 2002; Autor, 2014; Mishel, Schmitt and Shierholz, 2014; Autor, Manning and Smith, 2016).

Finally, models help in stitching the available explanations together. Despite all the efforts, this process of hunting for causes and verifying implications of models leaves us with a set of possible explanations. No single model can fully explain the rising skill premium in the 1980s. Recall that this was just one aspect of the rising inequality in the U.S. For its other aspects, economists developed other possible causal scenarios, considered more models, and tried to verify their explanations. The story is similar: no single model can explain other aspects of inequality in the U.S., let alone explain all its aspects. No single conclusive explanation emerges. Nevertheless, attempts to explain various aspects of inequality are not independent of each other. In fact, approaching the same fact from different dimensions help us cross check the plausibility of a set of possible scenarios with related possible scenarios. Extensive review articles commonly try to stitch together explanations of different aspects of a given fact (such as inequality in the U.S.) and expose inconsistencies between the available explanations (see, for example, Gordon and Dew-Becker, 2008). This process of stitching explanations together is also guided by available models. If the models share a set of principles and assumptions (e.g., profit and utility maximization) this guides the stitching process. As in our example, the supply and demand model helps to formulate how models relate to each other in explaining different aspects of the phenomenon in question (e.g., see Autor, 2014).

As Rodrik argues, social reality is complex and for this reason we do not always arrive at complete and correct explanations. The outcome of this complex and painful process of identifying, describing, measuring, exploring, conjecturing, verifying, and stitching is usually a patchwork of the most likely causal scenarios. Of course, inequality is a complex phenomenon and maybe this was to be expected. But consider an apparently simpler explanation-seeking question: why does popcorn cost so much at movie theaters in the U.S.? This question turns out be a difficult one to answer. As in the case of inequality in the U.S., economists formulate possible explanations of high popcorn prices at theaters, and try to determine which one (or which combination) of these explanations is more likely be the correct answer. But no single completely satisfactory answer emerges (McKenzie, 2008; Landsburg, 2012). 
Nevertheless, the process described above gives us better ideas about which scenarios are more likely and how the causal factors cited by various scenarios might have interacted. Even if we do not have conclusive explanations, there is progress in the sense that our explanations are moving in the right direction.

\section{Better explanations?}

Let us now consider how having a diversity of models could improve a singular explanation. A singular explanation is an answer to a specific explanation-seeking question concerning a particular fact or event. The question is specific in the sense that it asks why one thing happened rather than something else. For example, our question was why the wage gap between skilled and unskilled workers increased in the 1980s rather than not increasing given the conditions of the U.S. economy in that period. Stated like this, the question constrains the amount of explanatory information needed to fully answer it. What we expect economics to provide us with is relevant pieces of information that would help us answer this question.

If we were able to provide an ideal explanation, ${ }^{6}$ this explanation would cite all the relevant factors that are responsible for the explanandum phenomenon given the explanatory task at hand. Such an ideal explanation would provide a complete answer to the explanation-seeking question that we were trying to answer. The ideal explanation, as the name suggests, is an ideal. In practice, scientists (economists included) commonly fall short of providing us with ideal explanations. Rather, they try to get closer to the ideal explanation by way of supplying the bits and pieces of explanatory information needed to provide that explanation. An ideal explanation of the wage gap between skilled and unskilled workers in U.S. would provide us with a list of factors that contribute to this inequality, inform us about how these factors interacted and present evidence concerning their relative contributions. Although economists did not provide us with everything we needed to know, they provided us with explanatorily relevant information about the parts of the process of this increasing inequality. In the previous section, we have seen that having a diversity of models played an important role in the process by way of helping economists provide explanatory information. It is in this sense that the diversity of models helps economists in getting closer to providing a correct and complete answer to an explanation-seeking question about a particular real-world economic phenomenon.

It is certainly true that we now have a better understanding of the increasing wage gap between skilled and unskilled workers in the 1980s in the U.S. In Section 5, we have seen that "why did this gap increase?" was only one of the many questions that we could ask about increased inequality in the U.S. For this reason, merely answering this question is not sufficient for a better understanding of the inequality in the U.S., which requires the answers to a larger number of questions concerning the other aspects of inequality. More generally, our understanding of it depends on our ability to ask and answer a large set of what-if questions and to see the connections between these answers (Ylikoski and Aydinonat, 2014). A diversity of models is also valuable in these respects. It increases our ability to ask and answer a large number of interrelated what-if questions. In this sense, the diversity of models is also a means to a better understanding of economic phenomena.

\section{Conclusion}

Because social reality is complex, and because no single model can account for it immediately, providing singular explanations in economics is difficult. As in the case of inequality in the

${ }^{6}$ On 'ideal explanatory text', see Railton $(1978,1981)$. 
U.S. the process can take several decades and in the end a conclusive explanation may not emerge. Nevertheless, in dealing with the complexity of the real world, using multiple models to investigate aspects of the phenomenon in question appears to be a better strategy than using complex but opaque models. By way of allowing economists to tackle different aspect of the explanandum from multiple angles, and helping them to verify possible causal scenarios, diversity of models helps economists unearth the truths about their explanandum. Diversity of models helps us provide explanatory information about several relevant aspects of the phenomenon to be explained. In this sense, the diversity of models is a means to better explanations in economics.

Providing singular explanations in economics is a complex process that cannot be summarized with a single recipe. Nevertheless, provided that there is already a set of established theoretical models concerning a given explanatory task, we can summarize the process of moving from models to singular explanations in the following steps.

(i) Determine the set of models that are relevant for the explanatory task,

(ii) Assemble a list of possible explanations from the menu of possible explanatory factors which are suggested by this set of models,

(iii) Empirically verify which of these factors are actually causing the fact or event to be explained,

(iv) If available models fail to lead to a satisfactory explanation, look for other relevant models, or build new models to expand the menu of possible explanations, and

(v) Repeat the preceding steps until a satisfactory explanation is found.

This list is not meant to summarize what an individual economist does or should do to provide an explanation. Rather, it characterizes the collective process of providing modelbased explanations. At any given time, individual economists are likely to work on different steps simultaneously. Moreover, if the original explanatory task turns out to be too complicated, it will be divided into manageable sub-tasks (i.e., a big question will be divided into smaller and simpler questions) and these sub-tasks will be tackled by various economists at various times. As models, evidence, and the answers to manageable questions accumulate, the ability of economists to answer to larger and more difficult questions could also improve.

I have argued that economists often explain using multiple models, and that the diversity of models could be considered as a means to better explanations in economics. I would like to conclude with two take-home messages. The first one is for philosophers of economics. Most philosophical accounts of models focus on the relation between $a$ model and its target (Knuuttila, 2009). Philosophers of economics rarely take the multiplicity and diversity of economic models into account. Moreover, the link between models and explanation is an understudied subject. If Rodrik is right, and if my exposition of the several ways in which models can contribute to explanations is correct, then philosophers of economics ignore the diversity of economic models and their services to explanations at their peril. The second lesson is for economists. Although there are exceptions like Dani Rodrik, most economists take the philosophical questions concerning their models rather too lightly. Moreover, as Rodrik argues, "very little research is devoted to what might be called economic diagnostics: figuring out which among multiple plausible models actually applies in particular, real-world settings" (Rodrik, 2017, p. 141). This is interesting because, as the preceding discussion shows, models play many roles in economics, and there is no easy route from theoretical models to singular explanations. Although, the diversity of models in economics could be considered as a means to better explanations, the multiplicity and diversity of models could 
also lead us to problems like an embarrassment of riches (Grüne-Yanoff and Marchionni, 2018). Obviously, economists need to reflect on how they use their models and make their diagnostic strategies explicit. Both practicing economists and students will benefit from such reflection.

Acknowledgements. I would like to express my thanks to Aki Lehtinen, Caterina Marchionni, Dingmar van Eck, Don Ross, Francesco Guala, Jaakko Kuorikoski, Jack Vromen, John Davis, Roderick W. McConchie, Till Grüne-Yanoff, Uskali Mäki, and Wade Hands for their comments and suggestions.

\section{References}

Autor, D. H. (2010) 'The Polarization of Job Opportunities in the U.S. Labor Market', The Center for American Progress and The Hamilton Project Working Paper. Available at: https://www.brookings.edu/wp-content/uploads/2016/06/04_jobs_autor.pdf.

Autor, D. H. (2014) 'Skills, education, and the rise of earnings inequality among the "other 99 percent”", Science, 344(6186), pp. 843-851. doi: 10.1126/science.1251868.

Autor, D. H., Manning, A. and Smith, C. L. (2016) 'The Contribution of the Minimum Wage to US Wage Inequality over Three Decades: A Reassessment', American Economic Journal: Applied Economics, 8(1), pp. 58-99. doi: 10.1257/app.20140073.

Aydinonat, N. E. (2008) The invisible hand in economics: how economists explain unintended social consequences. London: Routledge.

Borenstein, S. and Netz, J. S. (1999) 'Why do all the flights leave at 8 am?: Competition and departure-time differentiation in airline markets', International Journal of Industrial Organization, 17(5), pp. 611-640. doi: 10.1016/S0167-7187(97)00058-1.

Boumans, M. (2006) 'The Difference Between Answering a "Why" Question and Answering a "How Much” Question', in Lenhard, J., Küppers, G., and Shinn, T. (eds) Simulation: Pragmatic Construction of Reality. Dordrecht: Springer, pp. 107-124. doi: 10.1007/1-4020-5375-4_7.

Boumans, M. (2009) 'Understanding in Economics: Grey-Box Models', in de Regt, H., Leonelli, S., and Eigner, K. (eds) Scientific Understanding: Philosophical perspectives. Pittsburgh: University of Pittsburgh Press, pp. 210-228.

Bound, J. and Johnson, G. (1992) 'Changes in the Structure of Wages in the 1980's: An Evaluation of Alternative Explanations', The American Economic Review, 82(3), pp. 371392. Available at: www.jstor.org/stable/2117311.

Card, D. and DiNardo, J. (2002) 'Skill-Biased Technological Change and Rising Wage Inequality: Some Problems and Puzzles', Journal of Labor Economics, 20(4), pp. 733-783. doi: $10.1086 / 342055$.

Coyle, D. (2014) GDP: A Brief but Affectionate History. Princeton University Press.

Eaton, B. C. and Lipsey, R. G. (1989) 'Chapter 12 Product differentiation', Handbook of Industrial Organization, Volume 1, pp. 723-768. doi: http://dx.doi.org/10.1016/S1573448X(89)01015-0.

Ehrenberg, R. G. and Smith, R. S. (2012) Modern Labor Economics: Theory and public policy. 11th edn. Boston: Prentice Hall. 
Feenstra, R. C. and Hanson, G. H. (1995) 'Foreign investment, outsourcing and relative wages', NBER Working paper, (No. 5121). doi: 10.3386/w5121.

Feenstra, R. C. and Hanson, G. H. (1997) 'Foreign direct investment and relative wages: Evidence from Mexico's maquiladoras', Journal of International Economics, 42(3-4), pp. 371-393. doi: 10.1016/s0022-1996(96)01475-4.

Friedman, M. (1953) 'The Methodology of Positive Economics', in Essays in Positive Economics. Chicago: The University of Chicago Press, pp. 3-43.

Gibbard, A. and Varian, H. R. (1978) 'Economic Models', The Journal of Philosophy, 75(11), pp. 664-677.

Gilboa, I. et al. (2014) 'Economic models as analogies', Economic Journal, 124(578), pp. 513533. doi: 10.1111 /ecoj.12128.

Giorgi, G. M. (1990) 'Bibliographic portrait of the Gini concentration ratio', METRON International Journal of Statistics, XLVIII(1-4), pp. 183-221.

Gordon, R. J. and Dew-Becker, I. (2008) 'Controversies About the Rise of American Inequality: A Survey', NBER Working Paper, (No. 13982). doi: 10.3386/w13982.

Grüne-Yanoff, T. and Marchionni, C. (2018) 'Modelling model-selection in model pluralism', Journal of Economic Methodology.

Hotelling, H. (1929) 'Stability in competition', The Economic Journal, 39(153), pp. 41-57. doi: 10.1007/978-1-4613-8905-7_4.

Knuuttila, T. (2009) 'Isolating Representations Versus Credible Constructions? Economic Modelling in Theory and Practice', Erkenntnis. Springer Netherlands, 70(1), pp. 59-80. doi: 10.1007/s10670-008-9137-7.

Kuorikoski, J., Lehtinen, A. and Marchionni, C. (2010) 'Economic Modelling as Robustness Analysis', The British Journal for the Philosophy of Science, 61(3), pp. 541-567. doi: 10.1093/bjps/axp049.

Landsburg, S. E. (2012) The Armchair Economist. 2nd edn. London: Simon \& Schuster.

Levy, F. and Murnane, R. J. (1992) 'U.S. earnings levels and earning inequality: A review of recent trends and proposed explanations', Journal of Economic Literature, 30(3), pp. 13331381.

Lorenz, M. O. (1905) 'Methods of Measuring the Concentration of Wealth', Publications of the American Statistical Association, 9(70), p. 209. doi: 10.2307/2276207.

Mäki, U. (1992) 'On the Method of Isolation in Economics', Poznan Studies in the Philosophy of the Sciences and the Humanities, 26(special issue (ed. C. Dilworth) Idealization IV: Intelligibility in Science), pp. 319-354.

Mäki, U. (2005) 'Models are experiments, experiments are models', Journal of Economic Methodology, 12(2), pp. 303-315. doi: 10.1080/13501780500086255.

Mäki, U. (2011) 'Models and the locus of their truth', Synthese, 180(June 2009), pp. 47-63. doi: 10.1007/s11229-009-9566-0. 
McKenzie, R. B. (2008) Why Popcom Costs So Much at the Movies. New York, NY: Springer New York. doi: 10.1007/978-0-387-77001-7.

Mishel, L., Schmitt, J. and Shierholz, H. (2014) 'Wage Inequality: A Story of Policy Choices', New Labor Forum, 23(3), pp. 26-31. doi: 10.1177/1095796014544325.

Morgan, M. S. (1999) 'Learning from Models', in Morgan, M. S. and Morrison, M. (eds) Models as Mediators: Perspectives on Natural and Social Science. Cambridge: Cambridge University Press, pp. 347-388.

Morgan, M. S. (2001) 'Models, stories and the economic world', Journal of Economic Methodology, 8(3), pp. 361-384. doi: 10.1080/13501780110078972.

Morgan, M. S. (2002) 'Model experiments and models in experiments', in Magnani, L. and Nancy J. Nersessian (eds) Model-based reasoning: Science, Technology, V alues. New York: Kluwer Academic/Plenum Publishers, pp. 41-45.

Netz, J. S. and Taylor, B. a. (2002) 'Maximum or Minimum Differentiation? Location Patterns of Retail Outlets', Review of Economics and Statistics, 84(1), pp. 162-175. doi: 10.1162/003465302317331991.

Odenbaugh, J. (2005) 'Idealized, inaccurate but successful: A pragmatic approach to evaluating models in theoretical ecology', Biology and Philosophy, 20(2-3), pp. 231-255. doi: 10.1007/s10539-004-0478-6.

Pielou, E. C. (1981) 'The Usefulness of Ecological Models: A Stock-Taking', The Quarterly Review of Biology. University of Chicago Press, 56(1), pp. 17-31. Available at: http://www.jstor.org/stable/2826368.

Railton, P. (1978) 'A Deductive-Nomological Model of Probabilistic Explanation', Philosophy of Science, 45(2), pp. 206-226. doi: 10.1086/288797.

Railton, P. (1981) 'Probability, explanation, and information', Synthese, 48(2), pp. 233-256. doi: 10.1007/BF01063889.

Rodrik, D. (2015) Economics Rules: Why Economics Works, When It Fails, and How To Tell The Difference. Oxford: Oxford University Press.

Rodrik, D. (2017) The straight talk on trade: ideas for a sane world economy. Princeton: Princeton University Press.

Ruben, D.-H. (2012) Explaining Explanation. 2nd edn. London: Routledge.

Sugden, R. (2000) 'Credible worlds: the status of theoretical models in economics', Journal of Economic Methodology, 7(1), pp. 1-31. doi: 10.1080/135017800362220.

Sugden, R. (2009) 'Credible Worlds, Capacities and Mechanisms', Erkenntnis. Springer Netherlands, 70(1), pp. 3-27. doi: 10.1007/s10670-008-9134-x.

Sugden, R. (2011) 'Explanations in search of observations', Biology and Philosophy, 26(5), pp. 717-736. doi: 10.1007/s10539-011-9280-4.

Sugden, R. (2013) 'How fictional accounts can explain', Journal of Economic Methodology, 20(3), pp. 237-243. doi: 10.1080/1350178X.2013.828872. 
Varian, H. R. (2009) Intermediate Microeconomics: A Modern Approach. W.W. Norton \& Company.

Wimsatt, W. C. (1987) 'False Models as Means to Truer Theories', in Nitecki, M. H. and Hoffman, A. (eds) Neutral Models in Biology. Oxford: Oxford University Press, pp. 2355.

Woodward, J. (1984) 'A theory of singular causal explanation', Erkenntnis, 21(3), pp. 231262. doi: $10.1007 / \mathrm{BF} 00169275$.

Woodward, J. (2003) Making things happen: A theory of causal explanation. Oxford: Oxford University Press.

Woodward, J. (2006) 'Some varieties of robustness', Journal of Economic Methodology. Routledge, 13(2), pp. 219-240. doi: 10.1080/13501780600733376.

Ylikoski, P. and Aydinonat, N. E. (2014) 'Understanding with theoretical models', Journal of Economic Methodology, 21(1), pp. 19-36. doi: 10.1080/1350178X.2014.886470. 